\title{
Cuticle-degrading Enzymes of Entomopathogenic Fungi: Regulation of Production of Chitinolytic Enzymes
}

\author{
By RAYMOND J. ST LEGER, * RICHARD M. COOPER AND \\ A. KEITH CHARNLEY \\ School of Biological Sciences, University of Bath, Claverton Down, \\ Bath BA2 7AY, UK
}

(Received 10 February 1986)

\begin{abstract}
Synthesis of chitinase and chitosanase by the entomopathogenic fungus Metarhizium anisopliae is regulated by products of chitin and chitosan degradation through an inducer-repressor mechanism. Slow-feeding with sugars or alanine (about $20 \mu \mathrm{g} \mathrm{ml}^{-1} \mathrm{~h}^{-1}$ ) in a carbon deficient medium to prevent catabolite repression (restricted cultures) demonstrated that the most effective inducers of chitinase and chitosanase were the principal monomeric constituents of chitin ( $N$-acetylglucosamine) and chitosan (glucosamine) respectively. Increasing the rate of release of $N$-acetylglucosamine decreased chitinase synthesis by about $87 \%$ while causing a sevenfold increase in growth. In batch cultures high chitinase activities were present only in chitin-containing medium. There was a negative correlation between accessibility and amount of chitin substrates, levels of free $\mathrm{N}$-acetylglucosamine in culture fluids and chitinase production. Addition of carbohydrates, lipid or proteins to chitin-grown cultures repressed chitinase production. Basal levels of chitinase were produced in non-inducing media. Production of chitobiase ( $N$-acetylglucosaminidase) was enhanced from high basal levels by amino sugars, but was less inducible and less susceptible to catabolite repression than chitinase.
\end{abstract}

\section{INTRODUCTION}

The entry of entomopathogenic fungi through the relatively massive barrier presented by the insect cuticle is considered to occur by a combination of mechanical pressure and enzymic degradation, but the relative importance of the two mechanisms is not known (Charnley, 1984). Several entomopathogenic fungi such as Metarhizium anisopliae, Beauveria bassiana and Verticillium lecanii, when grown in liquid cultures containing locust cuticle as sole carbon source, produce a variety of hydrolytic enzymes with activity against the major components of insect cuticle, namely protein, chitin and lipid (St Leger et al., 1986a). Before a role in parasitism can be assigned to these enzymes it is desirable to understand how their synthesis is regulated. This will give an insight into how production may be regulated by cuticle components. It will also enable culture conditions to be established for selective biosynthesis of specific cuticledegrading enzymes (CDE) or for critical comparison of enzyme production by mutants or isolates which differ in pathogenicity.

Many enzymes with exogenous substrates are inducible and many inducible enzymes are subject to catabolite repression (see Cooper, 1977). It is likely that CDE of entomopathogenic fungi are also subject to this regulation. However, in contrast to critical studies on regulation of polysaccharide-degrading enzymes of several plant pathogens (Collmer \& Bateman, 1981; Cooper \& Wood, 1975; Cooper, 1977), much work on regulation of chitinase production by bacteria and fungi has involved long-term trials in batch cultures under non-gratuitous conditions in which such fundamental considerations as the effects of catabolite repression,

Abbreviations: CDE, cuticle-degrading enzymes; GIcNAc, $N$-acetylglucosamine. 
growth rates, autolysis and changes in $\mathrm{pH}$ have been ignored or insufficiently allowed for (see Charnley, 1984). Consequently little progress has been made in determining the mode of regulation of chitinase synthesis and in evaluating its contribution to cuticle penetration (Charnley, 1984). Chitin exists as organized chains of poly- $N$-acetylglucosamine, forming some $25-40 \%(\mathrm{w} / \mathrm{w})$ of insect cuticle (Neville, 1975), and represents a potential barrier to invasion.

Many difficulties encountered in previous studies can be avoided or minimized by supplying as sole carbon source potential inducers at low constant rates so that growth is restricted and catabolite repression prevented. This can be achieved using diffusion capsules (Pirt, 1971) which provide a rapid and highly reproducible technique applicable to shake-flask cultures (Cooper \& Wood, 1975). This device was used to examine the regulation of chitinolytic enzymes by the causative agent of green muscardine disease, $M$. anisopliae.

\section{METHODS}

Growth conditions. M. anisopliae (ME1) (origin: Pecan weevil) was obtained from Tate and Lyle, Group Research and Development Laboratory, Reading, UK. It was maintained on Sabouraud's Dextrose Agar at $27^{\circ} \mathrm{C}$ and stored at $4{ }^{\circ} \mathrm{C}$. Cultures were grown in $250 \mathrm{ml}$ Erlenmeyer flasks containing a carbon source in 50 or $100 \mathrm{ml}$ basal salts medium, pH 5.8 (Cooper \& Wood, 1975) shaken on a rotary incubator $\left(150\right.$ r.p.m.) at $27^{\circ} \mathrm{C} ; \mathrm{NaNO}_{3}$ was omitted from media if the carbon source also functioned as a source of nitrogen (i.e. chitin or amino sugars).

Restricted cultures were grown under similar conditions except that they were maintained at around $\mathrm{pH} 6 \cdot 0$ with $0.05 \mathrm{M}$-MES buffer.

Supply of carbon source. Carbon sources were either supplied in an 'unrestricted' manner at $0.2-3 \%(\mathrm{w} / \mathrm{v})$, or the supply was restricted to the approximate rate of utilization by means of diffusion capsules (Pirt, 1971; Cooper \& Wood, 1975). Rates were controlled by altering the concentration of solutes inside capsules and the number of membranes through which diffusion occurred. Capsules containing monosaccharides $(30 \%, \mathrm{w} / \mathrm{v})$ and three membrane layers gave linear diffusion rates of about $20 \mathrm{\mu g} \mathrm{ml}^{-1} \mathrm{~h}^{-1}$ over $20 \mathrm{~h}$, so that capsules needed to be changed only once daily. To ensure linear release with one membrane layer (about $80 \mu \mathrm{g} \mathrm{ml}^{-1} \mathrm{~h}^{-1}$ ) capsules were changed twice daily.

Sterilization. Culture media were sterilized by autoclaving at $121^{\circ} \mathrm{C}$ for $15 \mathrm{~min}$. Sugars and amino acids were sterilized by membrane filtration (Oxoid membrane filters) under reduced pressure. Empty diffusion capsules were washed in absolute ethanol, and then autoclaved with carbon sources (except glucosamine) at $115^{\circ} \mathrm{C}$ for 10 min before placing in cultures. Glucosamine was filter sterilized and added to autoclaved diffusion capsules.

Inocula. Unrestricted cultures were inoculated with conidia $\left(3 \times 10^{4}\right.$ spores $\left.\mathrm{ml}^{-1}\right)$, unless stated otherwise.

Standardized inocula for experiments in which diffusion capsules were used were prepared from $3 \mathrm{~d}$ shake cultures containing $1 \%$ sucrose. Mycelium was removed by centrifugation $(1800 \mathrm{~g}, 15 \mathrm{~min})$ and then washed in sterile distilled water and centrifuged. The mycelial pellets from three or four flasks were used as the inoculum for each restricted culture.

The mean dry weight of the pellets from individual flasks was $31 \mathrm{mg} \pm 2 \cdot 14(\mathrm{SE}, n=9)$. This level of reproducibility allowed comparisons within and between experiments.

Assays of cultures. Samples were taken from each flask at intervals, and filtered through Whatman no. 1 filter paper and centrifuged $\left(1800 \mathrm{~g}, 15 \mathrm{~min}, 1^{\circ} \mathrm{C}\right.$ ). Filtrates were analysed for $\mathrm{N}$-acetylglucosamine (GlcNAc) (Reissig et al., 1955), reducing sugars (Nelson, 1944) and protein (dye binding; Bio-Rad); they were assayed for enzymes (see below) after dialysis against about 200 vol. stirred distilled water at $\mathrm{pH} 6.0$ for $14 \mathrm{~h}$. Fungal growth was measured by the methods described by St Leger et al. (1986a).

Enzyme substrates. Technical grade crab chitin (reportedly 30-35\%,w/w, protein: Smith \& Grula, 1983) and purified crystalline chitin (suitable for enzyme assays) were from Sigma; both were water insoluble. 'Ground chitin' was comminuted $(<0.2 \mathrm{~mm}$ particle size) using a Glen-Creston hammer mill. Colloidal chitin was prepared with $\mathrm{H}_{3} \mathrm{PO}_{4}$ (St Leger, 1985). Colloidal chitosan (a polymer composed primarily of glucosamine residues) was prepared from crystalline chitosan (Sigma) by the method of Monaghan (1973).

Enzyme assays. The $\mathrm{pH}$ optima of dialysed enzymes were determined and the enzymes assayed at these $\mathrm{pH}$ values as described by St Leger et al. (1986a). Chitinase (EC 3.2.1.14) activity (against crystalline or colloidal chitin) and chitosanase (EC 3 2.1.99) activity (against colloidal chitosan) were assayed at $\mathrm{pH} 5 \cdot 3$ using Nelson's (1944) modification of the Somogyi method observing the precautions outlined by Marais et al. (1966). Results are expressed as $\mu \mathrm{mol}$ amino sugar released $\mathrm{ml}^{-1} \mathrm{~h}^{-1}$. Chitobiase activity (formerly EC 3.2.1.29) against chitobiose (Sigma) was assayed at pH 5.0 using the modification of the Morgan-Elson procedure of Reissig et al. (1955) and is expressed as $\mu \mathrm{mol} \mathrm{GlcNAc}$ released $\mathrm{ml}^{-1} \mathrm{~h}^{-1}$. Purification (unpublished data) revealed that chitobiase and $N$ acetyl- $\beta$-D-glucosaminidase (EC 3.2.1.30) activities are identical. Specific activities are not given for batch cultures because of the high levels of protein introduced into culture media with 'technical grade' chitin.

Chemicals. All other chemicals used were of analytical grade, and were supplied by Sigma or BDH. 
Table 1. Effect of different carbon sources on growth, $\mathrm{pH}$ and extracellular chitinase production in $5 d$ cultures

All cultures were inoculated with $3 \times 10^{6}$ conidia except for $(a)$ (with $1 \%$ chitin as carbon source) which was inoculated with $1 \times 10^{4}$ conidia. Each result is the mean of three replicates $\pm \mathrm{SE}$. The experiment was repeated once (data not shown) with comparable results.

\begin{tabular}{|c|c|c|c|c|c|}
\hline Carbon source & Final $\mathrm{pH}$ & $\begin{array}{c}\text { Extracellular } \\
\text { protein } \\
\left(\mu \mathrm{g} \mathrm{ml} \mathrm{ml}^{-1}\right)\end{array}$ & $\begin{array}{c}\text { Chitinase } \\
\text { activity } \\
(\mu \mathrm{mol} \mathrm{GlcNAc} \\
\left.\mathrm{ml}^{-1} \mathrm{~h}^{-1}\right)\end{array}$ & $\begin{array}{l}\text { Reducing } \\
\text { groups } \\
\text { in medium } \\
\left(\mu \mathrm{g} \mathrm{ml}^{-1}\right)\end{array}$ & $\begin{array}{c}\text { Growth* } \\
\text { (mg per } 50 \mathrm{ml})\end{array}$ \\
\hline $1 \%$ Chitin & $7.05 \pm 0.14$ & $59.3 \pm 4.65$ & $1.34 \pm 0.21$ & $5 \pm 1 \cdot 5$ & +++ \\
\hline $1 \%$ Chitin $^{a}$ & $6.85 \pm 0.17$ & $13.5 \pm 1.73$ & $0.24 \pm 0.04$ & $90 \pm 16.5$ & +++ \\
\hline $2 \%$ Chitin & $6.89 \pm 0.07$ & $83.4 \pm 8.58$ & $1.47 \pm 0.15$ & $11 \pm 1.5$ & $+++t$ \\
\hline $3 \%$ Chitin & $7.49 \pm 0.21$ & $97.4 \pm 8.91$ & $0.69 \pm 0.09$ & $70 \pm 6.6$ & $+t+t$ \\
\hline $1 \%$ Colloidal chitin & $8.14 \pm 0.13$ & $134.2 \pm 9.62$ & $0.10 \pm 0.03$ & $176 \pm 21 \cdot 0$ & $++t+$ \\
\hline $1 \%$ Chitosan & $7.62 \pm 0.16$ & $32 \cdot 6 \pm 5 \cdot 10$ & $0.54 \pm 0.09$ & $38 \pm 7.5$ & ++++ \\
\hline $0.2 \%$ GlcNAc & $6.82 \pm 0.19$ & $15.3 \pm 1.48$ & $0.14 \pm 0.02$ & $294 \pm 20 \cdot 6$ & $36 \pm 1.6$ \\
\hline $0.5 \%$ GlcNAc & $6.44 \pm 0.26$ & $20.5 \pm 2.58$ & $0.10 \pm 0.01$ & $385 \pm 28.0$ & $84 \pm 5.5$ \\
\hline $1.0 \%$ GlcNAc & $6.50 \pm 0.04$ & $30.6 \pm 4.17$ & $0.03 \pm 0.00$ & $802 \pm 11.5$ & $163 \pm 11 \cdot 7$ \\
\hline $1 \%$ Cellulose & $6.15 \pm 0.26$ & $8.0 \pm 1.00$ & 0 & - & ++ \\
\hline $\begin{array}{l}\text { cellulose } \\
\text { collo }\end{array}$ & $6.80 \pm 0.14$ & $17.2 \pm 1.79$ & $0.01 \pm 0.00$ & - & +++ \\
\hline $1 \%$ Pectin & $6.00 \pm 0.28$ & $95.8 \pm 9.99$ & $0.01 \pm 0.00$ & 0 & +++ \\
\hline $1 \%$ Sucrose & $6.18 \pm 0.14$ & $41 \cdot 3 \pm 8 \cdot 70$ & $0.04 \pm 0.02$ & $>1000$ & $48 \pm$ \\
\hline $1 \%$ Lactose & $6.11 \pm 0.26$ & $33.0 \pm 3.34$ & $0.01 \pm 0.00$ & $>1000$ & $15 \pm$ \\
\hline $1 \%$ Xylan & $6.05 \pm 0.13$ & $13.2 \pm 1.94$ & 0 & $6 \pm 1.5$ & $9 \pm$ \\
\hline oluble starch & $6.73 \pm 0.15$ & $73.4 \pm 9.53$ & $0.02 \pm 0.00$ & $41 \pm 8 \cdot 3$ & $27 \pm$ \\
\hline
\end{tabular}

- With insoluble carbon sources, growth was estimated using an arbitrary scale ranging from + (poor growth) to +++++ (luxuriant growth). The scale can be approximated with mycelial growth (dry wt in $50 \mathrm{ml} \mathrm{GlcNAc/basal} \mathrm{salts} \mathrm{media)} \mathrm{as}+(<15 \mathrm{mg}),++(15-50 \mathrm{mg}),+++(50-100 \mathrm{mg}),++++(100-$ $150 \mathrm{mg}),++++(>150 \mathrm{mg})$.

\section{RESULTS}

\section{Chitinase synthesis during growth on various carbon sources in batch cultures}

Initially the effects of different carbon sources on growth and chitinase production were tested in unbuffered basal medium supplemented with chitin, glucose, GlcNAc or one of the other carbon sources listed in Table 1 . After incubation for $5 \mathrm{~d}$, cultures were harvested and analysed for growth, $\mathrm{pH}$ and, following dialysis, for chitinase activity. Appreciable growth occurred on all of the carbon sources tested, but high chitinase activities were only found in cultures supplied with chitin. Addition of cycloheximide $\left(10 \mu \mathrm{g} \mathrm{ml}^{-1}\right)$ to $3 \mathrm{~d}$ cultures containing chitin inhibited the production of chitinase. Growth on GlcNAc (the monomer of chitin) at concentrations less than $0.5 \%$ resulted in slightly more enzyme than was obtained with other non-chitinous monomers or polymers (Table 1). At higher GlcNAc concentrations, chitinase production was apparently repressed. Chitinase production was also repressed when additional carbon sources such as carbohydrates, olive oil or protein were added to a medium containing chitin (Table 2).

Small amounts of chitinase (about $3 \%$ of fully induced levels) were produced in media not containing chitin. Fig. 1 shows growth and extracellular chitinase activity in cultures containing sucrose as the sole carbon source. Growth declined after $5 \mathrm{~d}$ whereas chitinase activity increased gradually throughout. Lipase, which is mainly endocellular, appeared extracellularly principally during autolysis (unpublished data); in sucrose culture media this occurred only after $5 \mathrm{~d}$ when microscopic examination revealed hyphal lysis in the centre of mycelial pellets.

\section{Influence of chitin concentration and particle size on chitinase production}

For studying the effect of chitin concentration and particle size, basal medium was prepared as described but with different concentrations and preparations of chitin, viz. $1 \%$ unground (about $0.5 \mathrm{~mm}$ particle size) chitin, 1, 2 and $3 \%$ ground $(<0.2 \mathrm{~mm}$ particle size) chitin and $1 \%$ 


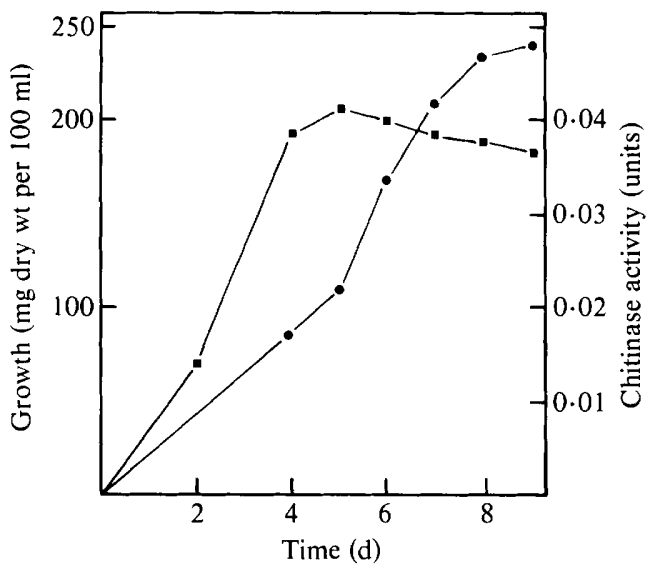

Fig. 1

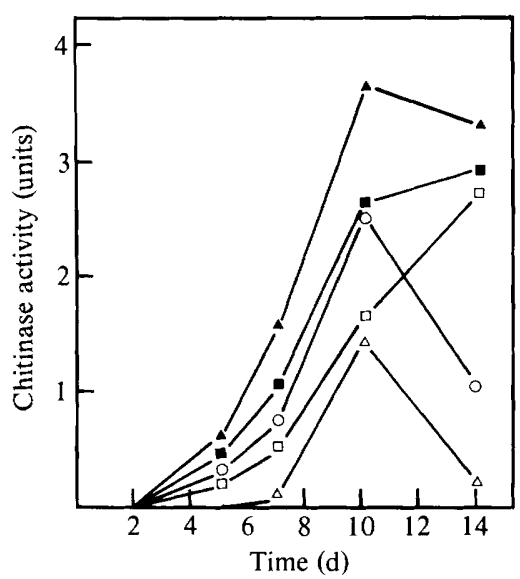

Fig. 2

Fig. 1. Growth and chitinase activity in $1 \%$ sucrose/basal salts medium. $\mathbf{D}$, Mycelial dry weight; $\boldsymbol{O}$, chitinase activity. Each point is the mean of three replicates. The experiment was repeated once (data not shown) producing similar results.

Fig. 2. Effect of chitin concentration and particle size on the production of chitinase. Growth media contained $1 \%$ unground chitin $(\square), 1 \%(\square), 2 \%(\mathbf{\Delta})$ or $3 \%(O)$ ground chitin, or $1 \%$ colloidal chitin $(\triangle)$.

\section{Table 2. Effect of chitin and additional carbon sources on chitinase production in} $5 d$ cultures

M. anisopliae (ME1) was grown on $1 \%$ chitin plus the additional carbon source stated. Each result is the mean of three replicates \pm SE. The experiment was repeated once (data not shown) with comparable results.

\begin{tabular}{|c|c|c|c|c|}
\hline $\begin{array}{l}\text { Additional } \\
\text { carbon } \\
\text { source }\end{array}$ & Final $\mathrm{pH}$ & $\begin{array}{c}\text { Extracellular } \\
\text { protein } \\
\left(\mu \mathrm{g} \mathrm{m}^{-1}\right)\end{array}$ & $\begin{array}{c}\text { Chitinase } \\
\text { activity } \\
(\mu \mathrm{mol} \mathrm{GlcNAc} \\
\left.\mathrm{ml}^{-1} \mathrm{~h}^{-1}\right)\end{array}$ & Growth* \\
\hline None & $7.05 \pm 0.14$ & $59.3 \pm 4.65$ & $1.34 \pm 0.21$ & +++ \\
\hline $0.2 \%$ Glc NAc & $6.76 \pm 0.17$ & $35 \cdot 3 \pm 4 \cdot 19$ & $0.07 \pm 0.00$ & +++ \\
\hline $1.0 \%$ GlcNAc & $6.77 \pm 0.08$ & $64.2 \pm 3.78$ & $0.03 \pm 0.00$ & ++++ \\
\hline $1.0 \%$ Peptone & $7.48 \pm 0.13$ & $74.3 \pm 5.61$ & $0.49 \pm 0.09$ & $+++t$ \\
\hline $0.01 \mathrm{M}$-Cysteine & $6.43 \pm 0.21$ & $90.3 \pm 8.73$ & $0.24 \pm 0.08$ & ++++ \\
\hline $0.5 \%$ Casamino acids & $7.81 \pm 0.20$ & $112.4 \pm 7.62$ & $0.11 \pm 0.02$ & ++++ \\
\hline $0.2 \%$ Tween 80 & $6.72 \pm 0.11$ & $43.2 \pm 7.57$ & $1.06 \pm 0.10$ & +++ \\
\hline $0.5 \%$ Olive oil & $6.88 \pm 0.25$ & $68.4 \pm 9.34$ & $0.21 \pm 0.00$ & $+++t$ \\
\hline $0.5 \%$ Sucrose & $6.32 \pm 0.04$ & $56.7 \pm 5.23$ & $0.06 \pm 0.00$ & +++ \\
\hline
\end{tabular}

* Estimated using an arbitrary scale (see Table 1).

colloidal chitin. Altering the accessibility of chitin to the fungus in this way had a strong influence on growth and chitinase production (Fig. 2, Table 1). Growth was greatest on $3 \%$ ground and $1 \%$ colloidal chitin. However, the highest chitinase activity was produced with $2 \%$ ground chitin (Figs 2 and 3, Table 1). Less chitinase was present with $1 \%$ unground chitin than on $1 \%$ ground chitin, but $1 \%$ colloidal chitin (the most accessible form) resulted in comparatively low chitinase activity. This was especially apparent in young $(<5 \mathrm{~d})$ cultures in which the contribution of autolysis to total chitinase is negligible. Fig. 3 shows the change in $\mathrm{pH}$ and formation of chitinolytic enzymes in one experiment with altered forms of chitin. In all cultures there was a close correlation in patterns of appearance of activities against crystalline and colloidal chitin. However, activity against chitobiose was not related to production of chitin-degrading enzymes and probably resulted from a different enzyme. 

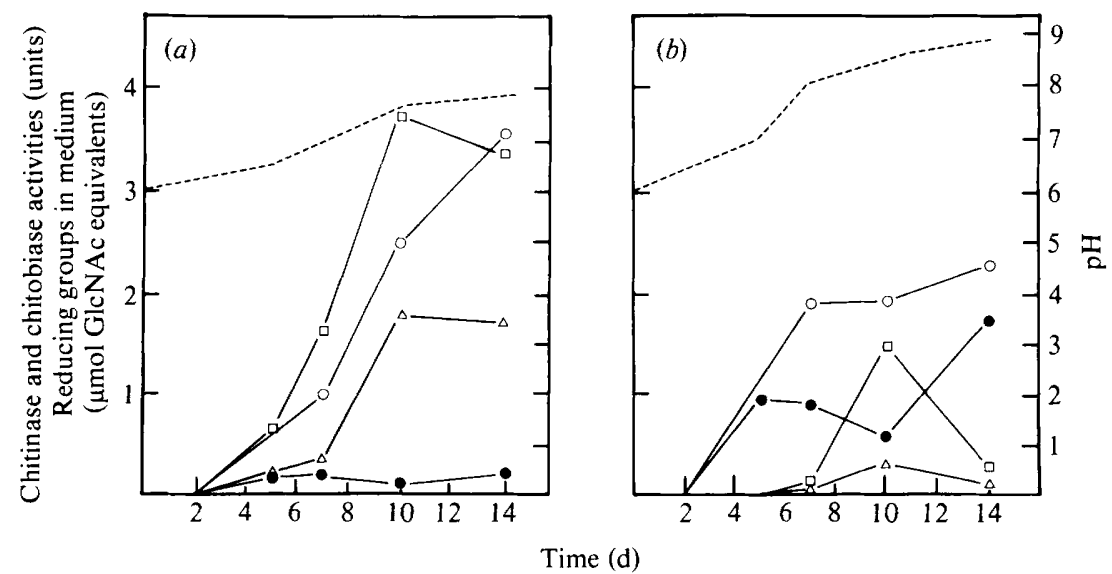

Fig. 3. Chitinase and chitobiase production in a basal salts medium containing $(a) 2 \%$ ground crystalline chitin or (b) $1 \%$ colloidal chitin. Chitinase was assayed with colloidal chitin ( $\square$ ) or crystalline chitin $(\triangle)$; chitobiase $(O)$ was assayed with chitobiose. Reducing sugars in the medium; ,$--- \mathrm{pH}$. Each point is the mean of three replicates. The experiment was repeated once (data not shown) producing similar results.

High amounts of reducing sugars were detected in fluids from cultures grown on $3 \%$ ground and $1 \%$ colloidal chitin (Table 1 ).

In all cultures there was a rapid increase in $\mathrm{pH}$ during production of chitinolytic enzymes. The $\mathrm{pH}$ of the medium may affect the stability and possibly the release of extracellular chitinase (unpublished data); therefore, MES-buffered medium ( $\mathrm{pH} \mathrm{6.0)}$ was used in later experiments with restricted carbon source supply.

An additional bias in these results could result from degradation or activation of chitinase by the two serine proteases from $M$. anisopliae (St Leger et al., 1986a). Chitinase in culture fluids (containing high levels of proteases) was stable over $12 \mathrm{~h}$ at $27.5^{\circ} \mathrm{C}$. Inhibition of serine protease activity (with $2 \times 10^{-4} \mathrm{M}$ phenylmethylsulphonyl fluoride) did not alter chitinase activity, indicating that it is resistant to proteolysis by enzymes of this organism.

\section{Induction of chitinolytic enzymes in restricted feed cultures}

To avoid or restrict catabolite repression, various sugars or alanine, the major amino acid of insect cuticle (St Leger et al., 1986a), were fed as potential inducers from diffusion capsules to shake cultures of $M$. anisopliae (ME1) containing standardized mycelial inocula (see Methods). The concentration of supplied sugars after $4 \mathrm{~d}$ was $\leqslant 7 \mu \mathrm{g} \mathrm{ml}^{-1}$, indicating that they were being utilized by the fungus at approximately the rate of diffusion. Consequently, growth was limited by the restricted rate of supply and was considerably less $(1 / 7$ th in the first $2 \mathrm{~d})$ than that in media containing 'unrestricted' amounts of a suitable carbon source (Fig. 4). Levels of chitinase production under these conditions are summarized in Figs 4 and 5 and Table 3. Basal levels of chitinase (about $7 \%$ of maximum specific activity) were produced with restricted supplies of glucose. Production of chitinase was induced by GlcNAc, the predominant monomer of chitin, and to a significantly lesser extent by glucosamine. The induction ratio (induced enzyme)/(basal enzyme) was between 20 and 150 (Tables 1 and 3).

The results (Table 3) indicate that $M$. anisopliae (ME1) produced at least two enzymes, distinct from chitinase, that degrade chitosan and chitobiose. In contrast to chitinase the chitosanase was induced to a similar extent by glucosamine and GlcNAc. Basal levels of enzyme (about $5 \%$ of the maximum) were produced when mycelium was supplied with restricted glucose. The separate identities of chitinase, chitosanase and chitobiase were confirmed after purification (unpublished data). Highest levels of chitobiase occurred with GlcNAc and to a lesser extent glucosamine, but substantial amounts were also produced with alanine $(\leqslant 75 \%$ of the maximum). 


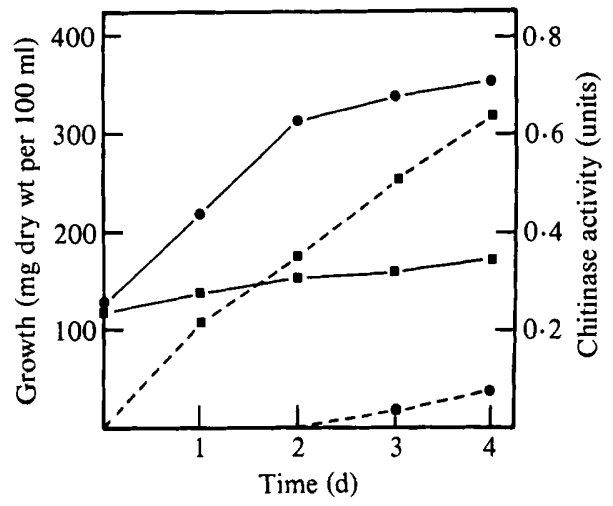

Fig. 4. Growth (-) and chitinase activity (----) in the presence of GlcNAc. 9 , Unrestricted culture, initial GlcNAc concentration $1 \% ; \boldsymbol{\square}$, restricted culture, diffusion rate about $20 \mu \mathrm{g} \mathrm{m}^{-1} \mathrm{~h}^{-1}$.

Table 3. Induction of synthesis of CDE of $M$. anisopliae (ME1) by a restricted supply of monosaccharides or alanine

Enzyme activities [units (mg extracellular protein) $)^{-1} \pm \mathrm{SE}, n=5$ ] are those attained after $4 \mathrm{~d}$ exposure to different carbon sources. Values expressed as a percentage of the highest activity are shown in parentheses.

Inducer*

GlcNAc

Glucosamine

Glucose

Galacturonic acid

Alanine
Chitinase $†$

$\begin{array}{rr}19.93 \pm 1.50 & (100.0) \\ 13.92 \pm 1.60 & (69.8) \\ 1.48 \pm 0.23 & (7.4) \\ 1.27 \pm 0.19 & (6.4) \\ 0.92 \pm 0.17 & (6.2)\end{array}$

Chitosanase

$12.09 \pm 1.46$
$13.44 \pm 1.34$
$0.63 \pm 0.11$
$0.72 \pm 0.08$
$0.65 \pm 0.14$

Chitobiase $\S$

$(90 \cdot 0)$

$\begin{array}{lr}44.12 \pm 3.04 & (100.0) \\ 37.13 \pm 2.95 & (84.2) \\ 26.95 \pm 1.54 & (61.1) \\ 18.00 \pm 1.64 & (40.8) \\ 32.40 \pm 1.86 & (73.4)\end{array}$

* Inducers were fed from diffusion capsules to established mycelium ( $93 \mathrm{mg}$ dry wt) at linear rates of about $20 \mu \mathrm{g} \mathrm{ml}^{-1} \mathrm{~h}^{-1}$. Means were compared using Student's $t$-test (see footnotes $+, \ddagger, \S$ ).

† Chitinase: GlcNAc or glucosamine vs other carbon sources, $P<0.001$; GlcNAc vs glucosamine, $0.05>P>0.02$

$\$$ Chitosanase: GlcNAc or glucosamine vs other carbon sources, $0.002>P>0.001$; GlcNAc vs glucosamine, difference not significant.

$\S$ Chitobiase: GlcNAc vs glucosamine, $0.05>P>0.02$; GlcNAc vs glucose, $0.01>P>0.001$; glucosamine vs glucose or galacturonic acid, $0.02>P>0.01$; glucosamine vs alanine, difference not significant.

\section{Effect of rate of supply of GlcNAc on chitinase synthesis}

To test for sensitivity to catabolite repression, supplies of GlcNAc were increased in restricted cultures so that eventually supply exceeded the requirements of the organism and sugars accumulated to high levels in the media. Cultures of $M$. anisopliae (ME1) were grown for $4 \mathrm{~d}$ with GlcNAc supplied from diffusion capsules at about 20 and $80 \mu \mathrm{g} \mathrm{ml}^{-1} \mathrm{~h}^{-1}$. Increasing the rate of supply decreased the synthesis of chitinase by about $87 \%$ while causing a sevenfold increase in growth (Fig. 5). Reducing group determination showed that GlcNAc, when supplied at $20 \mu \mathrm{g} \mathrm{ml}^{-1} \mathrm{~h}^{-1}$, never exceeded $30 \mu \mathrm{g} \mathrm{ml}^{-1}$ in culture fluids. At the higher supply rate, however, GlcNAc accumulated in cultures to as much as $1 \mathrm{mg} \mathrm{m}^{-1}$.

These values suggest that GICNAc may cause catabolite repression of the chitinase when in excess of the immediate growth requirements of the organism. In comparison the effect on chitobiase production of catabolite repression was considerably less. Increasing the rate of supply increased synthesis of chitobiase by about $170 \%$. This is however, a smaller increase than would be expected if levels of extracellular enzyme were related entirely to mycelial growth. 


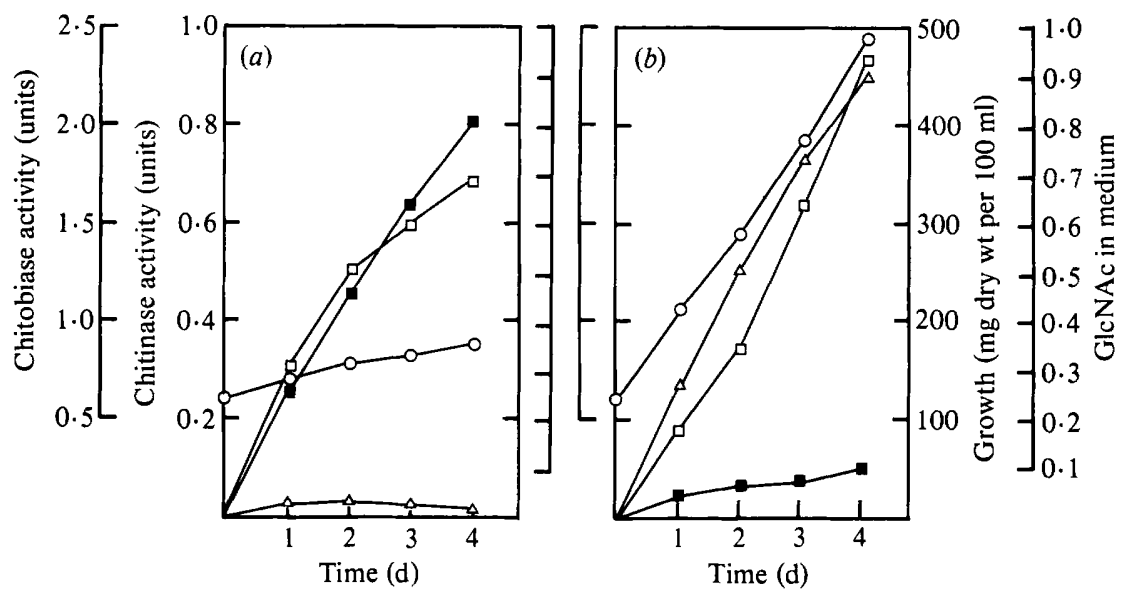

Fig. 5. Chitinase and chitobiase production with GlcNAc supplied at (a) $20 \mu \mathrm{g} \mathrm{ml}^{-1} \mathrm{~h}^{-1}$ and (b) $80 \mu \mathrm{g}$ $\mathrm{ml}^{-1} \mathrm{~h}^{-1}$. $\square$, Chitinase activity; $\square$, chitobiase activity; $O$, growth; $\triangle$, GlcNAc content of the medium. Each result is the mean of three replicates. The experiment was repeated once (data not shown) producing similar results.

\section{DISCUSSION}

Previously we reported (St Leger et al., 1986a) that chitinase and chitobiase activities appeared after enzymes of the proteolytic complex when $M$. anisopliae, B. bassiana and $V$. lecanii were grown on locust cuticle. It was suggested that the late appearance of chitinase could be the result of induction as chitin eventually becomes available after degradation of encasing cuticle proteins (St Leger et al., 1986a,b). This might parallel the later production of inducible cellulases (cf. matrix-degrading enzymes when plant pathogens are grown on host cell walls: Cooper, 1977, 1983), or might reflect release of adsorbed chitinase from chitin following solubilization of the polymer from cuticle (St Leger et al., 1986c). The work described in this paper confirms that chitinase synthesis is regulated by products of chitin degradation through an inducer-repressor mechanism. High chitinase activity was found only in cultures supplied with chitin, but not with other polymers such as pectin, xylan and cellulose, which is indicative of induction; a repressible constitutive enzyme should have also appeared in high levels on polysaccharides which, especially in insoluble forms, may be insufficient to produce catabolite repression (Cooper, 1977). Slow-feeding of $M$. anisopliae (ME1) with sugars or alanine in a carbon deficient medium demonstrated that the most effective inducer of chitinase was GlcNAc, the principal monomeric constituent of chitin. Induction of chitinase synthesis is apparently not specific to GIcNAc as glucosamine also allowed production of the enzyme. This may be an adaptation by the fungus to the fact that chitin from natural sources appears to be partially deacetylated (Hackman \& Goldberg, 1965, 1974; Rudall \& Kechington, 1973), while chitosan also contains 10-20\% acetylated residues (Monaghan, 1973). Therefore, apparent chitinase activity might be partly due to chitosanase activity on deacetylated parts of the chitin. The converse, however, is unlikely to be true as most reports suggest that chitosan is not attacked by chitinase (e.g. Karrer \& White, 1930; Monreal \& Reese, 1969; Nord \& Wadstrom, 1972).

Besides the monomer, other candidates for inducers of chitinase are soluble oligomers of chitin (Monreal \& Reese, 1969). By analogy with cellulases (the two polymeric substrates are chemically, physically and functionally similar) which are induced by the dimer cellobiose (Cooper \& Wood, 1975; Cooper 1977; 1983), chitobiose might be expected to induce chitinase. It is relevant therefore, that as with cellulose (Preston, 1974) the disaccharide is the stereochemical repeating unit of $\alpha$-chitin (Carlstrom, 1962); also, at least one well characterized chitinase, that of Streptomyces spp., releases chitobiose from colloidal chitin as the major degradation product (Berger \& Reynolds, 1958; Skujins et al., 1970). However, it seems unlikely 
for two reasons that chitobiose could function as a major inducer of chitinase activity in $M$. anisopliae (ME1). Firstly, extracellular and cell-bound activities of the constitutive chitobiase would probably degrade chitobiose to GlcNAc before it enters the cell (in culture fluids chitinase was never found in the absence of chitobiase). Secondly, the major product released by both chitobiase and pure chitinase is GlcNAc (unpublished data).

Observations with batch cultures showed a negative correlation between growth rate and enzyme production. In addition, maximum enzyme activities attained in cultures were inversely related to the accessibility of the chitin substrate. A similar situation has been described for cellulases and the results have also been interpreted in terms of catabolite repression (e.g. Horton \& Keen 1966; Yamane et al., 1970).

Although greater loss of soluble activity would be expected with more finely divided forms of chitin, as chitinase adsorbs to its substrate (St Leger et al., 1986c), analysis of batch culture fluids confirmed that inducing sugars had accumulated to repressive levels in cultures where extracellular enzyme activity was low (e.g. on $3 \%$ chitin, or with $1 \%$ colloidal chitin: Table 1 ). These results suggest that whether the fungus is living saprotrophically in debris containing chitin, or penetrating insect cuticle, the accessibility and amount of chitin relative to other available nutrients including cuticular protein and lipid may determine levels of chitinase synthesized through the inducer-repressor system.

Some chitinase in older $(>5 \mathrm{~d})$ cultures seemed to be released passively from autolysing hyphae; endocellular enzymes such as lipase also appeared after this time. However, the low levels of chitinase in non-inducing media may not solely result from autolysis, as basal levels of inducible enzymes are often detectable in the absence of inducer (Cooper \& Wood, 1975; Cooper, 1977). Basal synthesis was apparent in young cultures (which lacked endocellular lipase activity) supplied with restricted levels of non-inducing sugars.

An interesting contrast to the mode of regulation of chitinase was provided by chitobiase which was produced in all media and was little affected by catabolite repression. The reasons for this relatively loose control over synthesis are not known but may reflect a continuing function of this enzyme in cell wall changes during growth. Although unlikely to be an adequate explanation for its largely constitutive production, extracellular chitobiase will probably function along with basal levels of chitinase to release inducers of chitinase from chitin. It is noteworthy that chitobiase but not chitinase effectively degrades the dimer and trimer of GlcNAc (unpublished data).

The control of chitinase by induction and catabolite repression allows certain other data to be re-interpreted. Monreal \& Reese (1969), using unrestricted batch cultures of Serratia marcescens, found production of far greater amounts of chitinase on chitin than on GlcNAc, and they suggested induction was probably by soluble oligomers. However, as more chitinase was produced on low concentrations of GlcNAc $(0.2 \%)$ than on higher concentrations, induction and catabolite repression by the monomer is a probability. Moreover, Young \& Carroad (1981) demonstrated in the same strain of $S$. marcescens that chitinase was produced in restricted feed cultures with GlcNAc as limiting substrate. Unfortunately, they did not test any alternative carbon sources in limiting amounts so control by catabolite repression alone cannot be ruled out. However, taking their work in conjunction with that of Monreal \& Reese (1969), it seems probable that chitinase in $S$. marcescens is regulated by GlcNAc induction and catabolite repression in a similar way to chitinase in $M$. anisopliae (ME1).

In unrestricted batch cultures of $B$. bassiana, amino sugars allowed production of small quantities of chitinase ( $36 \mu \mathrm{g}$ GlcNAc released over $4 \mathrm{~h}$ from $0.5 \mathrm{ml}$ concentrated $1 \% \mathrm{GlcNAc}$ medium), whereas no chitinase was detected in cultures containing glucose or amino acids (Smith \& Grula, 1983). It is possible, therefore, that even under conditions where catabolite repression is presumably operating, there is still some specificity of induction (Cooper \& Wood, 1975). B. bassiana and Penicillium islandicum produce chitosanases when grown on Rhizopus hyphae, whereas growth on colloidal chitin or colloidal chitosan does not induce the enzyme (Monaghan, 1973). It was suggested that the induction of chitosanase requires the presence of the substrate as it exists in nature, i.e. in hyphae or cells walls. Chitosan in Rhizopus hyphae is presumably inaccessible compared with colloidal preparations and it seems probable, therefore, 
that these results can be explained in terms of catabolite repression. A strain of $M$. anisopliae studied by Monaghan (1973) did not apparently produce a chitosanase suggesting there may be considerable variation between isolates of this species in the specificity of their chitinolytic enzymes.

Finance for this study was provided by Bath University and the AFRC.

\section{REFERENCES}

Berger, L. R. \& Reynolds, D. M. (1958). The chitinase system of a strain of Streptomyces griseus. Biochimica et biophysica acta 29, 522-534.

CARLSTROM, D. (1962). The polysaccharide chain of chitin. Biochimica et biophysica acta 59, 361-364.

Charnley, A. K. (1984). Physiological aspects of destructive pathogenesis in insects by fungi; a speculative review. In Invertebrate-Microbial Interactions, pp. 229-270. British Mycological Society Symposium 6. Edited by J. M. Anderson, A. D. M. Rayner \& D. W. H. Walton, Cambridge : Cambridge University Press.

Collmer, A. \& Batemam, D. F. (1981). Impaired induction and self-catabolite repression of extracellular pectate lyase in Erwinia chrysanthemi mutants deficient in oligogalacturonide lyase. Proceedings of the National Academy of Sciences of the United States of America 78, 3920-3924.

COOPER, R. M. (1977). Regulation of synthesis of cell wall-degrading enzymes of plant pathogens. In Cell wall Biochemistry Related to Specificity in Host-Plant Pathogen Interactions, pp. 163-211. Edited by B. Solheim \& J. Raa. Oslo: Universitetsforlaget.

COOPER, R. M. (1983). The mechanisms and significance of enzymic degradation of host cell walls by parasites. In Biochemical Plant Pathology, pp. 101135. Edited by J. A. Callow. New York: John Wiley.

COOPER, R. M. \& WoOd, R. K. S. (1975). Regulation of synthesis of cell wall-degrading enzymes by Verticillium albo-atrum and Fusarium oxysporum f. sp. lycopersici. Physiological Plant Pathology 5, 135-156.

Hackman, R. H. \& GoldberG, M. (1965). Studies on chitin. 6. The nature of $\alpha$ - and $\beta$-chitin. Australian Journal of Biological Science 18, 935-946.

HaCkmaN, R. H. \& GoldberG, M. (1974). Light scattering and infrared spectrophotometric studies on chitin and chitin derivatives. Carbohydrate Research 38, 35-45.

Horton, J. C. \& KeEN, N. T. (1966). Regulation of induced cellulase synthesis in Pyrenochaeta terrestris by utilisable carbon compounds. Canadian Journal of Microbiology 12, 209-220.

KarRer, P. \& White, S. M. (1930). Chitin. Helvetica chimica acta 13, 1105-1113.

Marais, J. P., DE WIT, J. L. \& Quickie, G. V. (1966). A critical examination of the Nelson-Somogyi Method for the determination of reducing sugars. Analytical Biochemistry 15, 373-381.

Monaghan, R. L. (1973). The discovery, distribution and utilization of chitosanase. PhD thesis, Rutgers University, NJ, USA.

Monreal, J. \& ReEse, E. T. (1969). The chitinase of Serratia marcescens. Canadian Journal of Microbiology 15, 689-696.

Nelson, N. (1944). A photometric adaptation of the Somogyi method for the determination of glucose. Journal of Biological Chemistry 153, 375-380.
Neville, A. C. (1975). Biology of the Arthropod Cuticle. Berlin: Springer-Verlag.

NoRD, C. E. \& WADSTROM, R. (1972). Chitinase activity and substrate specifity of three bacteriolytic endo- $\beta$ - $N$-acetyl-muraminidases and one endo- $\beta-N$ acetylglucosaminidase. Acta chemica scandanavica 26, 653-660.

Preston, R. D. (1974). The Physical Biology of Plant Cell Walls. London: Chapman \& Hall.

PIRT, S. J. (1971). The diffusion capsule, a novel device for the addition of a solute at a constant rate to a liquid medium. Biochemical Journal 121, 293-297.

Reissig, J. L., Strominger, J. L. \& Leloir, L. F. (1955). A modified colorimetric method for the estimation of $\mathrm{N}$-acetylamino sugars. Journal of Biological Chemistry 217, 959-966.

Rudall, K. M. \& Kenchington, W. (1973). The chitin system. Biological Reviews 49, 597-636.

ST LEGER, R. J. (1985). Cuticle-degrading enzymes of entomopathogenic fungi. $\mathrm{PhD}$ thesis, Bath University, UK.

St Leger, R. J., Charnley, A. K. \& Cooper, R. M. (1986a). Cuticle degrading enzymes of entomopathogenic fungi. Synthesis in culture on cuticle. Journal of Invertebrate Pathology (in the Press).

St Leger, R. J. \& CoOper, R. M., Charnley, A. K. $(1986 b)$. Cuticle degrading enzymes of entomopathogenic fungi; cuticle degradation in vitro by enzymes from entomopathogens. Journal of Invertebrate Pathology 47, 167-177.

St Leger, R. J., Charnley, A. K. \& Cooper, R. M. (1986c). Cuticle degrading enzymes of entomopathogenic fungi; mechanisms of interaction between pathogen enzymes and insect cuticle. Journal of Invertebrate Pathology 47, 295-302.

Skujins, J. J., Pukite, A. \& Mclaren, A. D. (1970). Chitinase of Streptomyces spp., purification and properties. Enzymologia 39, 353-370.

Smith, R. J. \& Grula, E. A. (1983). Chitinase is an inducible enzyme in Beauveria bassiana. Journal of Invertebrate Pathology 42, 319-326.

Stirling, J. L., Cook, G. A. \& Pope, A. M. S. (1979). Chitin and its degradation. In Fungal Walls and Hyphal Growth, pp. 169-188. British Mycological Symposium 2. Edited by J. H. Burnett \& A. J. P. Trinci. Cambridge: Cambridge University Press.

Yamane, K., Suzuki, H., Hirotani, M., Ozana, H. \& NisizaWA, K. (1970). Effect of nature and supply of carbon sources on cellulase formation in Pseudomonas fluorescens var. cellulosa. Journal of Biochemistry 67, 9-18.

Young, M. E. \& Carroad, P. A. (1981). Dependence of extracellular chitinase activity of Serratia marcescens QMB1466 on continuous culture dilution rate. Canadian Journal of Microbiology 27, 142-144. 